\title{
Development of Methods for Analysis and Assessment of the Efficiency of Regional Investment Projects Seeking State Support
}

\author{
Kseniya E. Azzheurova
}

Ph.D. in Economics, Associate Professor of "Accounting, Auditing and Analysis Department"

Southwest State University, Russia, Kursk; Email:kseniyaks2010@mail.ru

\section{Elena A. Bessonova}

Ph.D. in Economics, Professor, Head of "Accounting, Auditing and Analysis Department", Southwest State University Russia, Kursk; Email: bessonowa_new@mail.ru

\author{
Doi:10.5901/mjss.2015.v6n5s2p362
}

\begin{abstract}
Placing the economy of federal subjects of the Russian Federation in the trajectory of sustainable development, increasing its competitiveness are associated with the expansion and increase of effectiveness of investment activity in the regions. With present-day conditions in mind for improving the efficiency of functioning of regional economy one needs new tools and methods of management of regional investment projects based on the latest achievements of science and synthesis of international best experience. The article shows that the main aspect of management of regional investment projects is the analysis and estimation of their efficiency. It influences the pace of development, as well as solving regional socio-economic problems. The paper substantiates the necessity to complement the evaluation algorithm of regional investment projects with functional units of analysis of social, innovative, environmental consequences of projects. Basing on the systematization of the existing estimated figures, we propose the integrating efficiency indicator of assessment of regional investment projects efficiency. The article identifies the main methodological shortcomings in the regional practice of investment planning. Taking into account these shortcomings in the activities of regional authorities will create conditions for increasing the efficiency of administrative decisions in this field and on this basis will provide the dynamic development of a particular area. The authors develop a method of multi-criteria assessment of regional investment projects efficiency, which provides for the calculation of economic, social, innovative and environmental efficiency indicators, the application of the Pareto principle, the construction of vector diagrams enabling executive authorities to determine reasonably the priority directions of socio-economic policy. The results of the research have practical implications and can be used by local authorities in the selection of priority investment projects supported by public funding and guarantees, as well as in the preparation of regional special programs of socioeconomic development.
\end{abstract}

Keywords: regional investment project, analysis, efficiency assessment methods, socio-economic development

\section{Introduction}

The effectiveness of investment activity in the region largely depends on the validity of investment decisions taken by the executive authorities of the constituent entities of the Russian Federation while forming budget commitments for the next financial year. In the process of justification and selection of options of budget allocations, the goals of the regional administration differ from those of a private investor. If the key interests of the latter, in accordance with which the project to be financed is chosen, can be expressed in obtaining stable, high income and protection of capital against inflation, regional investment is aimed primarily at accelerating economic development of the region, increasing the technological competitiveness of the regional economy and the progress of its social sphere.

Under the conditions of own means deficit and the reduction of capital investment the successful development of the Russian Federation subjects requires not just increase in the volume of investments, but also the growth of effective investments that provide competitive advantages of regions (Azzheurova, Minakova, 2010). This means that regional authorities should use a wide range of tools for enhancing investment processes and raising capital. In this regard, there is an urgent need to improve methods of analysis and assessment of regional investment projects efficiency with the purpose of providing state administration, interregional, regional, municipal administration bodies and others with the necessary information for decision making. On should also note that the development of regional investment system directly depends on the rational management of regional investment projects. 


\section{Research Methodology}

Regional authorities regulate the process of development and implementation of regional investment projects on the territory of their entity using certain tools and methods of management. With their help, there can be formed resources, which are required for the regulation of investment processes. There can also be carried out practical activities that provide organizational impact of administrative structures on investment candidates. When deciding about the need for and scope of applying tools and methods of management of regional investment projects in each case it is necessary to consider the degree of their importance and complexity.

The process of management of regional investment projects is organized in such a way so that it should involve the basic functions of management, being based on a system of methods and tools by which regional authorities will be able to achieve necessary goals. The primary functions of regional investment projects management include the main activities of regional authorities, which are implemented at all levels and subject-matter areas while realizing regional investment projects (Azzheurova, 2012). The given management functions, their nature and tools are presented in Scheme 1.

One of the main aspects of regional investment projects management is the problem of analysis and assessment of their efficiency. The pace of development, as well as addressing socio-economic problems of the region depends on it. In its turn, the objectivity of the conducted analysis and assessment of regional investment projects efficiency is determined by the use of adequate methods. Assessment of regional investment projects efficiency should play a determining role in the choice of possible variants of budget allocations in the implementation of design decisions that will allow executive authorities to judge what price has to be paid to reach the stated objectives.

For further research, it is necessary to provide clarification regarding the interpretation of the concept of "regional investment project".

To determine the contemporary meaning of "the regional investment project" concept it is necessary to consider its social nature. With regard to this requirement, we propose the following economic interpretation of this term: the regional investment project is an investment project implemented in the territory of one or more subjects of the Russian Federation, contributing to employment growth and raising income of the population, broadening the tax base, easing social strain, stimulating innovation, environmental safety and having a significant impact on socio-economic development of the region. Giving an investment project the status of "regional" is a tool for implementing investment policy that would increase the inflow of investment resources in the region's economy and ensure sustainable economic growth. Therefore, a regional investment project must conform to the priorities of regional socio-economic development and provide positive social effects associated with its implementation. This is the specificity of the considered concept.

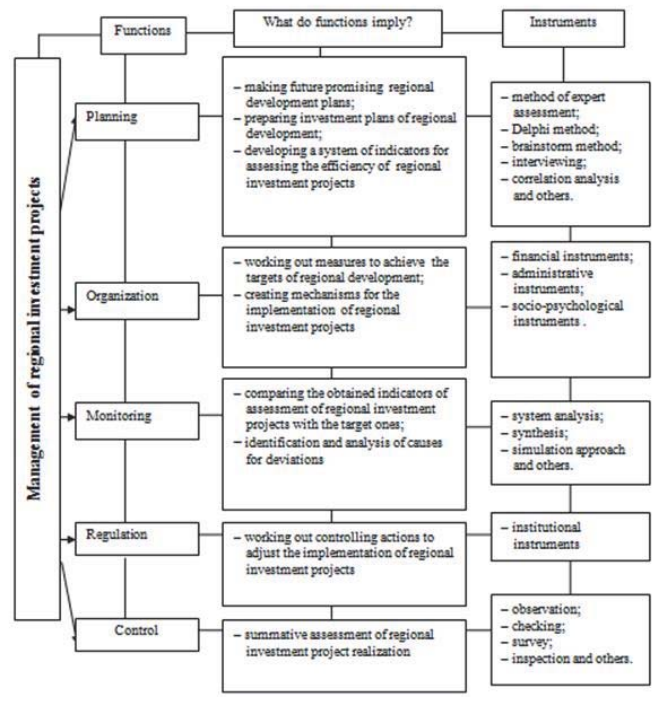

Scheme 1. The basic functions of regional investment projects management 
Regional investment projects being realized at the expense of budget funds must satisfy such general criteria as return of investments, the optimal ratio of the projected benefits and costs, positive social impact, environmental safety (Vodyanov, Gavrilova, Grishin, 2008). From the position of sustainable economic development and in addition to marked social effect resulting from the implementation of regional investment projects their innovative impact appearing in "the initiation" of limited budgetary funds of production sector development contributing to the increase of innovative activity in the region is of crucial importance here.

In our opinion, selection criteria for regional investment projects must meet the following requirements:

- Regional significance of an investment project being confirmed by inclusion in the regional target program with a formal decision about funding at the expense of the budget;

- having an exhaustive list of documents required for inclusion of investment projects in the program of socioeconomic development of the region;

- conformance of investment projects objectives to the priorities of socio-economic development of the regional economy;

- Positive innovation impact;

- meeting all the requirements of ecological safety in the region.

\section{The Main Part of Research}

The study revealed that the analysis is one of the main tools and methods of modern investment planning. The work on investment projects consists of a series of mutually agreed kinds of analysis - economic, technical, financial, institutional, commercial, environmental and social (Endovitskiy, 2010). Economic analysis of regional investment projects allows you to calculate the comparative evaluation of alternatives, to choose the most acceptable variant of investment options and to organize the subsequent continuous monitoring of implementation of investment projects according to the accepted system of indicators.

Comparing the options offered to support investment projects and selecting the best of them by regional authorities are made with the help of the following indicators: net present value (NPV), profitability index (PI), internal rate of return (IRR), payback period (PP); other indicators that reflect the interests of participants, such as modified internal rate of return, discounted payback period, return on investment.

In their works leading economists single out the main errors associated with the calculation of these indicators. The main discrepancies arise when using the indicator of «internal rate of return" (IRR) (Vilenskiy, Livshyts, Smolyak, 2008).

Firstly, the authors believe there is a common incorrect definition of IRR as the discount rate at which net present value (NPV) is equal to zero. The error is that the equation NPV $=0$ does not necessarily have a single positive root. In the case when there are no positive roots or there are more than one (which is quite possible), it is correct to assume that the IRR does not exist. It is also incorrect that the method of valuation on the basis of the IRR method is not worse than the method with the use of NPV. However, unlike the IRR the NPV indicator is always easy to calculate and by means of this indicator it is easier to evaluate the efficiency of a project. The greatest caution in the use of methods of IRR calculation should be observed in the comparison of different alternative investment projects or in their ranking. When solving these tasks there is a common misconception that the higher the IRR, the more effective an investment project.

Secondly, there is an erroneous opinion that the IRR of an investment project is its refinancing rate. In fact banks will not adjust their deposit rate of interest, on the basis of which the profit of a project is reinvested, depending on its riskiness and therefore discount rate.

Thirdly, it is also considered erroneous that the IRR of an investment project being realized entirely at its own expense is equal to the maximum lending rate at which this project being financed entirely through borrowing remains effective.

There also arise some methodological errors when using such indicators as profitability index (PI) and payback period (PP). The misconception related to the first indicator is that the higher it is, the more effective a project is. The above-mentioned authors believe that choosing the most efficient investment project among alternative ones on the basis of PI maximum may lead to more different conclusions than when choosing on the principle of NPV maximum that is it is theoretically and practically correct.

While applying a payback period (PP) indicator we are having the following wide spread misconception: the smaller it is, the better an investment project is. In reality, among alternative projects an investment project with the largest payback period often has the highest NPV. Moreover, there is no deterministic or correlative relationship between the value of payback period and the NPV of alternative projects. The main thing here is that the integrated effect of project realization should be maximum and positive (Vilenskiy, Livshits, Smolyak, 2008). 
There are also misconceptions about the economic content of indicators under discussion. There is a widespread misconception that the payback period is the time during which operational accounting profit accumulated in an investment project will reach the value of initial investment, and the sooner this happens the better the project is. Actually, this may not be so because of the loss of profit that is not included in the calculation of accounting profits.

Thus, it is necessary to consider the identified methodological flaws in the calculation of these indicators and to use comparative analysis to ensure the most effective financing of regional investment projects for the executive authorities of the Russian Federation subjects. Complex methodology of comparative analysis and selection of investment projects is based on the application of a number of different methods and techniques in a certain order. In particular, economic literature suggests using a methodology that includes three main blocks (Bystrov, Pozdnyakov, Prudnikov, Pertsov, 2008):

1) The formation of a set of indicators on the basis of which various governing bodies perform a comparative analysis of investment projects;

2) The consistent justification of the chosen investment projects on the basis of the Pareto principle, the Borda method and the BOF method (named after the author of this method - Bystrov Oleg Filaretovich);

3) The determination of the optimality criterion in order to form a portfolio of investment projects.

We should note that at present, there is no perfect method of assessing the efficiency of regional investment projects financed from the budget, which would take into account the nonprofit character of selecting the objectives of state support. Assessment of regional investment projects efficiency is of great scientific and practical interest, because the payback period of the invested capital, the pace of region development and the solution of many problems of local importance depend on how comprehensively this assessment is carried out. The objectivity of this assessment, in its turn, is largely determined by the use of modern methods of conducting such an assessment.

In modern practice to assess the efficiency of investment projects, especially of those into which are invested the state budget funds, one can use a cost - benefit analysis (CBA). Appropriate tools are considered reliable for making decisions regarding the allocation of budgetary resources in the social sphere. Cost-benefit analysis is practical in the cases where the impact of a social project will affect various aspects of life activity or when such a project is competing with other projects for the allocation of material resources relating to the social sphere. Involving value indicators within CBA gives it a quality of universality and allows us to apply it not only for the formation of a state investment programme for the next fiscal year, but also in the development of federal or regional target programmes (Kovalev, 2010).

We single out a number of interrelated principles of CBA of investment projects efficiency being realized with state participation. These projects may be applicable to any types of projects, including regional ones, regardless of their technical, technological or sectoral features.

1. The consideration of each investment project through its economic efficiency, allowing predicting the likely long-range effects.

2. The necessity of "national economy" approach, i.e. assessing the integrated efficiency of investment projects, reflecting the whole range of socio-economic impact of its implementation. In particular, this means taking into account not only direct, but also external results and costs concerning the related sectors of the economy, and also environmental, social and other non-economic effects.

3. The comparability of comparison conditions of various investment projects.

4. The evaluation of any investment project efficiency by comparing the situation "without project" and the situation with "project".

5. Considering the factor of time in various aspects, such as the impact of project parameters and its economic environment, the inequality of asynchronical costs and benefits.

6. The identification of the totality of costs to come. While calculating performance indicators one should take into account not only investments necessary for the implementation of an investment project, but also all capital expenditure and current costs in the period up to the completion of a project, as well as possible damage directly caused by the implementation of a project.

7. Cost calculation of all the benefits of an investment project. When determining the efficiency of an investment project one must identify all the benefits of its implementation, both direct and external. In those cases, when their role in achieving efficiency is not amenable to cost valuation, it is allowed to identify benefits using other methods of forecasting the results of investment projects realization.

The CBA method of investment projects efficiency is carried out with the use of tables, which define and calculate the total volume of investments, operating and maintenance costs, external costs, direct and external benefits of a project; net cash flow and performance indicators. The calculation of these parameters differs from the calculations within the analysis of projects being of a highly commercial nature (Kovalev, 2010).It should be noted that, the CBA method is 
used in the EU to assess only large-scale projects. This is due to the high complexity of such analysis, particularly in relation to identifying the effects of project activities. Therefore, to evaluate smaller-scale projects one can apply only particular elements and techniques of this methodology complemented by other existing approaches. In its turn, the application of CBA suggests the presence of a developed market of social services, information and statistical database needed to calculate the socio-economic effects of projects.

Thus, taking into account the specificity of the Russian market, regional authorities should consider the possibility of adapting the CBA methodology to the practice of assessing domestic regional investment projects implemented with government support.

In Russia methodological recommendations on the assessment of investment projects efficiency approved in 1999 by the RF Ministry of Economics, the RF Ministry of Finance, the State Committee of the Russian Federation on Construction, Architectural and Housing Policies play an important role in the process of management of investment projects, including regional ones. However, the methods based on the principles outlined in this document are not sufficient for reasoned decisions on budgetary financing of infrastructural, social, military-industrial and natural objects. Commercial approach to the definition of efficiency considers only the direct revenues and costs of a project, ignoring the consequences of its implementation for related kinds of production, products (services) users of the object being created.

When assessing investment projects, including regional ones, the main attention is usually paid to their actual economic results, which does not allow to objectively select projects that have social significance for a certain region. In our opinion, in this case you should consider the multiplier effect of all factors influencing the socio-economic development of a region. In this regard, we consider it necessary to supplement the existing algorithm for assessing regional investment projects with calculation of social, innovative and eco-efficiency (Fig. 2) (Azzheurova, Sergeev, 2012).

The criterion of "consistency of a regional investment project with the strategy of social and economic development of a region" involves the assessment of compliance with the objectives and expected results of a project, quantitative and qualitative target indicators and planned results of implementing the strategy for socio-economic development of a region. When assessing the efficiency of regional investment projects, regional authorities should consider how these investment projects fit into the strategic plan of regional development and whether they will contribute to achieving the set goals.

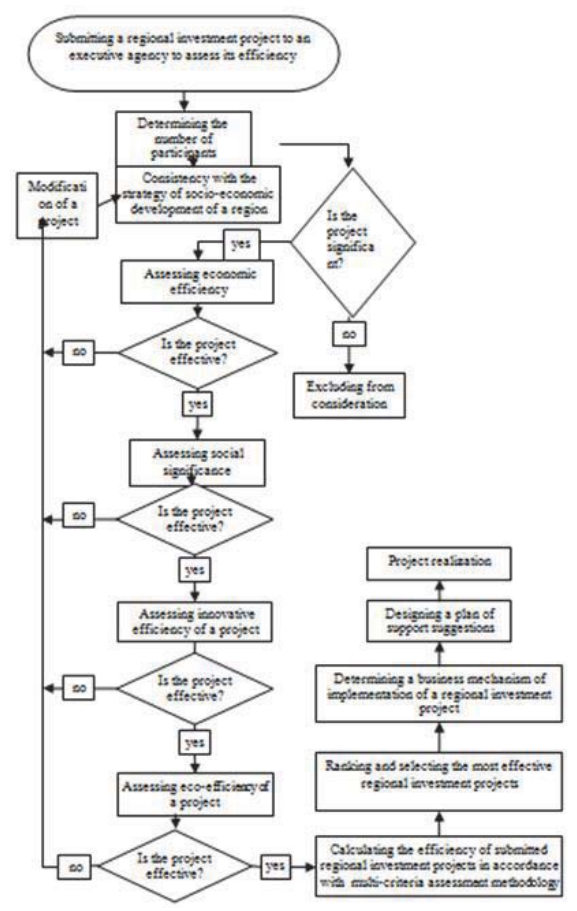

Scheme 2. The algorithm for assessing the efficiency of regional investment projects 
Further sequence of criteria assessment of the proposed algorithm is determined by expertise through a questionnairebased survey of interest groups in the development and implementation of regional investment projects: investors, community and authorities. In accordance with the obtained results these criteria were ranked in order of importance by the method of Churchmen-Ackoff (1 - cost effectiveness, 2 - social efficiency, 3 - innovative efficiency, 4 - ecological efficiency or eco-efficiency).

The factor of cost effectiveness is a set of estimates of cost and budget effectiveness. The value of the cost effectiveness criterion of regional investment projects is determined as the net present value of projects and the internal rate of return of projects (Broll, RoldánPonce, Wahl, 2013). The value of the budget effectiveness criterion of regional investment projects is determined as the ratio of discounted tax revenues to the budgets of different levels of budgetary system of the Russian Federation due to the implementation of these investment projects to discounted volume of budgetary allocations (Ageev, 2011).

The criterion of social efficiency allows us to consider the social impact of regional investment projects implementation and to fund (or support) projects that will provide the greatest benefit to society.

The main types of social effects to be reflected in the calculation of social impact are: increasing the level of employment in the region, health and longevity; supply of comfortable suitable dwellings to the population, accessibility and quality of public services for the population in transport, health, education, culture, improvement of the environment. Therefore, to achieve the effect regional social investment projects must contribute to solving a range of social objectives that are significant for the region. Thus, the magnitude of social impact is largely determined by the socio-economic situation in the region.

The importance of regional social effect is determined not only by absolute but also by relative indices, which characterize the influence of regional investment projects on the socio-economic development of regions. Every kind of social effects is determined by the corresponding calculation formula, which allows obtaining a quantitative assessment of a particular social effect owing to the implementation of a regional investment project.

The most important region's social indicators undergo an expert survey, the results of which are processed. Taking into account experts' knowledge there can be obtained the group estimates of social effects. We propose to determine the overall social effect from the implementation of a regional investment project on the basis of additive resultant of private coefficients of social effects.

In order to have better and multifactorial assessment of regional investment projects efficiency, it has been proposed to calculate their innovation efficiency. Innovation efficiency is the ability of a project to ensure the dynamic development of society by applying the latest achievements of scientific-technical progress (Morgunova, 2011). The criterion of "innovation efficiency" evaluates the contribution of regional investment projects to the innovative development of a region.

Assessment of eco-efficiency of regional investment projects is an independent indicator in connection with its significant impact on the lives and health of the population, the attractiveness of regions. This assessment is based on the analysis of environmental impact resulting from the implementation of regional investment projects and it allows through calculus of these environmental consequences in numerical terms to make a conclusion about the advisability and feasibility of a regional investment project considering account environmental factors.

Thus, in our opinion, taking into account social, environmental, innovation factors provides an integrated and comprehensive assessment of the efficiency of regional investment projects.

The conducted analysis of the existing methods of assessing investment projects efficiency, including regional ones, allowed us to conclude that for their evaluation a large number of indicators is used and is proposed to use, and they are often poorly coordinated. In order to identify the main methodological shortcomings of the existing approaches we conducted the analysis of system of indicators, which are used at present by the subjects of the Russian Federation to assess the efficiency of regional investment projects (Table. 1). 
Table 1 - System of estimated indicators of regional investment projects efficiency

\begin{tabular}{|c|c|c|c|}
\hline Result & Indicators & Criterion & Source \\
\hline Cost effectiveness & $\begin{array}{l}N P V=F C F_{0}+\sum_{t=1}^{T} \frac{F C F_{t}}{\prod_{i=1}^{t}\left(1+W A C C_{i}\right)}+\frac{V_{T}}{\prod_{t=1}^{T}\left(1+W A C C_{t}\right)} \\
\text { where } F C F_{0}-\text { net cash flow at the initial stage of regional investment } \\
\text { project realization; } F C F_{t}-\text { net cash flow in the period of } t ; W A C C_{\mathrm{i}(t)}- \\
\text { weighed average capital cost at the beginning of period } i(t) \text {, in the annual } \\
\text { quantities; } V_{T} \text { - continuing value of a project, or assessment of asset value, } \\
\text { created in the process of regional investment project realization at the point of } \\
\text { time } T ; T-\text { moment of time, restricting the period of direct forecasting of } \\
\text { cash flows of a regional investment project. } \\
N P V(I R R)=0 \Leftrightarrow F C F_{0}+\sum_{t=1}^{T} \frac{F C F_{t}}{(1+I R R)^{t}}+\frac{V_{T}}{(1+I R R)^{T}}=0\end{array}$ & IRR $>$ WACC & \multirow{2}{*}{$\begin{array}{l}\text { Order of the RF } \\
\text { Ministry of Regional } \\
\text { Development of } \\
\text { October } 30,2009, \text { No } \\
493 \\
\text { "On approval of } \\
\text { procedure for } \\
\text { calculation methods of } \\
\text { indicators } \\
\text { and application of } \\
\text { efficiency criteria of } \\
\text { regional investment } \\
\text { projects seeking state } \\
\text { support } \\
\text { at the expense of } \\
\text { budgetary } \\
\text { appropriations from } \\
\text { Investment Fund of the } \\
\text { Russian Federation" } \\
\text { (hereinafter referred to } \\
\text { as Order No 493) }\end{array}$} \\
\hline Budget effectiveness & $\begin{array}{l}P I b=\sum_{t=1}^{T} \frac{B C F_{t}}{(1+\bar{r})^{t}} / \sum_{t=1}^{T} \frac{I n v_{t}^{I F}}{(1+\bar{r})^{t}} \\
\text { where } B C F_{t} \text { - budget cash flow, generated by a regional investment project in } \\
\text { the period of } t ; \text { Inv } v_{t}{ }^{I F} \text { - the amount of state support in the year of } t ; \\
\text { required yield on injection of capital from the resources of the fund }\end{array}$ & $P I_{8}>1$ & \\
\hline Social efficiency & $\begin{array}{l}\text { 1) raising the employment rate of working age population; 2) increasing the } \\
\text { proportion of the population with comfortable housing; 3) improving the } \\
\text { availability and quality of public services in transport, health, education, } \\
\text { physical culture and sport, culture, housing and utilities; 4) improving the } \\
\text { living standards of the population; 5) improving demographic situation; 6) } \\
\text { optimizing migration flows. }\end{array}$ & $\begin{array}{l}\text { SOC }>\text { approved } \\
\text { regional } \\
\text { indicators } \\
\text { IntegratedSOC }\end{array}$ & $\begin{array}{l}\text { indicators 1-3(Order } \\
\text { No 493) } \\
\text { indicators 1-6 } \\
\text { (Sindyashkina, 2010) }\end{array}$ \\
\hline Innovation efficiency & $\begin{array}{l}\text { 1) the level of novelty of a project for the region (A1); 2) the level of using } \\
\text { technical and information technology (progressive, advanced, modern or } \\
\text { proven traditional technology) in a project (A2); 3) the level of using legally } \\
\text { protected results of scientific research and technological development } \\
\text { (patents, industrial designs, utility models, trademarks, inventions, know-how) } \\
\text { (A3); 4) the level of technical and operational study (presence of Research } \\
\text { and Advanced Development, laboratory, industrial designs, etc.) (A4); 5) the } \\
\text { share of research and highly qualified personnel (doctors and candidates of } \\
\text { sciences) to the total number of staff involved in a project (A5); } 6 \text { ) the } \\
\text { proportion of published scientific papers on the theme of a project being } \\
\text { aimed at the creation of fundamentally new types of products (A6). } \\
\text { Innov }=\sum_{i=1}^{n} a_{i} \times A_{i} \\
\text { where } a_{i}-\text { the significance of innovation component indicator } i\end{array}$ & Innov $>0,4$ & (Ruban, 2009) \\
\hline Eco-efficiency & $\begin{array}{l}\text { Integrated regional ecological effect } \\
\Im^{P \ni}=K^{C \ni \Pi} \times \sum_{\mathrm{t}=0}^{\mathrm{T}} \frac{\Phi_{t}^{\ni}}{(1+E)^{t}} \\
\text { where } K^{C \ni \Pi}-\text { coefficient of concordance of a project with regional } \\
\text { ecological goals; } \Phi_{t}^{\ni} \text { - ecological component of flow of funds; } E \text { - rate of } \\
\text { performance; } t \text { - calculation increment number }\end{array}$ & $\vartheta^{P 3}>0$ & (Nuzhina, 2010) \\
\hline $\begin{array}{l}\text { Integrated indicator of } \\
\text { efficiency assessment }\end{array}$ & $\begin{array}{l}O^{3}=\sum_{i=1}^{n} k_{i} \times \Pi_{i} \\
k_{i} \text { - the significance of efficiency assessment indicator } i_{;}, \Pi_{i}- \\
\text { rдe } \\
\text { efficiency assessment indicator } i\end{array}$ & $1 \leq 0^{3} \leq 10$ & (Azzheurova, 2012) \\
\hline
\end{tabular}

For integrated assessment of regional investment projects efficiency, we suggest using the integrating indicator, which includes four components: economic (NPV), social (SOC), innovation (Innov) and ecological (ERE).

The value of the integrating indicator is calculated as the sum of weighted averages for each type of efficiency. We propose to determine the weighting factors ki reflecting the relative importance of a given indicator in comparison with 
other estimates with the help of expert method "Delphi". The features of this method are: firstly, its simplicity; secondly, the identification of dominant individual judgments of experts without regard to the opinions of others; thirdly, possibility to obtain quantitative estimates which reflect objective reality through subjective judgments.

The calculation of total performance indicators are based on the calculation of specific indicators listed in Table 1, the number of which is determined by the specifics of each regional investment project and can vary depending on the direction of its realization.

The process of social impact assessment should be presented in a formalized manner, as it is not always possible to directly compare homogeneous indicators, for example, creating new jobs and reducing the existing ones. In most cases, it is necessary to compare different indicators, such as the reduction in the number of jobs in combination with wage increase for the remaining ones.

We propose to evaluate every kind of social effect in accordance with two criteria: the nature of influence (positive negative), the degree of impact effectiveness (low, medium and high). Here we can apply a point scale of estimation: low effect is estimated at 1 point, a significant effect at 5 points. Then different types of effects estimates are summarized and we can deduce the integrated assessment of social effect. You should use the qualitative assessment to compare the different types of social effects in cases where formal methods cannot be applied.

The choice of particular indicators of innovation efficiency is based on the requirements of logical consistency of these criteria with the innovative-investment process, scientific validity and objectivity, availability and simplicity of calculation, the specificity and uniqueness of results interpretation. Indicators A1 - A5 should be estimated by the following five-point scale: 1 - very high score, 4/5 - high score, 3/5 - satisfactory grade, 2/5 - low rating, 1/5 - a very low score.

For the calculation of the integrated index of regional ecological efficiency, a coefficient $K^{c \ni}$ is employed, the use of which will allow to exclude the possibility of implementing regional investment projects that do not meet goals of environmental security, and hence the socio-environmental development priorities of a region. We propose to evaluate the coefficient $K^{\complement \ni}$ by the expert method that is based on the following criteria:

1) the value of the coefficient is "1" - a regional investment project is in full compliance with the targets of environmental security in the region;

2) the value of the coefficient is " 0.75 " - the targets of environmental safety are implemented by $75 \%$;

3) the value of the coefficient is " 0,5 " - the targets of environmental safety are implemented by $50 \%$,

4) the value of the coefficient is " 0,25 " - the targets of environmental safety are implemented by $25 \%$;

5) the value of the coefficient is "0" - a regional investment project is not consistent with the targets of environmental security in the region.

The ecological component of cash flow $\Phi_{t}^{s}$ is determined as the difference between the inflow and outflow of funds. The norm of efficiency $E$ (in decimal terms) corresponds to the rate of discount at which $\vartheta^{P \ni}=0$.

The number of general indicators can be extended by means of calculating of such an indicator as budget efficiency of an investment project; however, it is not included in this methodology, since in most cases the authorities of the region do not participate in 100\% financing of regional investment projects due to budget constraints. They only use administrative methods of support, or they co-finance them in relatively small volumes.

As a result of our study, we have found out that while performing the procedure of assessment of regional investment projects efficiency, there can be met some methodological shortcomings due to the peculiarities of socioeconomic development of a region; the structure of assessment goals; the calculation of performance indicators; the clarification of the number of a project's participants for whom it is necessary to calculate efficiency; the identification of types of efficiency; the completeness of costs; the fairness of calculations; the influence of external and internal factors. The main methodological shortcomings of assessment of regional investment projects efficiency are the following:

1. Consideration of a narrow range of tasks by regional authorities in evaluating the efficiency of regional investment projects, which results in less effective choice of a project and the adoption of unsustainable management decisions.

2. Ignoring the possible environmental impacts arising from the implementation of regional investment projects. The main task of regional authorities is to assess environmental performance in order to determine the acceptability and feasibility of projects and to prevent possible negative consequences of their impact on the environment in the region. Hence, the main goal here is to create environmentally safe and comfortable living conditions of the population, places of work and leisure.

3. The lack of attention on the part of executive authorities to the innovative component in evaluating the efficiency of regional investment projects. The administration of the region should consider the innovative 
component in evaluating the efficiency of projects, as the most important condition of intensive regional development is the increase in innovative activity. This will ensure the growth of labor productivity and the dynamic development of society as a whole through the implementation of the latest achievements of scientific and technical progress.

The revealed deficiencies give rise to the necessity of developing the methods of multi-criteria evaluation of regional investment projects efficiency, which provides for the calculation of the integrating indicator, the use of the Pareto principle, the construction of the vector diagram according to the principle of "range of alternatives" and will allow regional authorities to determine the priorities of socio-economic policy (Fig. 3) (Azzheurova, 2012).

To choose the most priority regional investment project from a number of projects, the results of the integrated assessment are summarized. To perform this it is necessary to eliminate the differences in units of measurement of the obtained performance indicators using their scaling in the range from 0 to 10 points and bringing them to the point presentation.

Thus, as the weighing coefficients in total are equal to one, then the value of the integrating indicator of assessment of regional investment projects efficiency ranges from 0 to 10 . The higher the value of the integrating indicator, the more effective a regional investment project is.

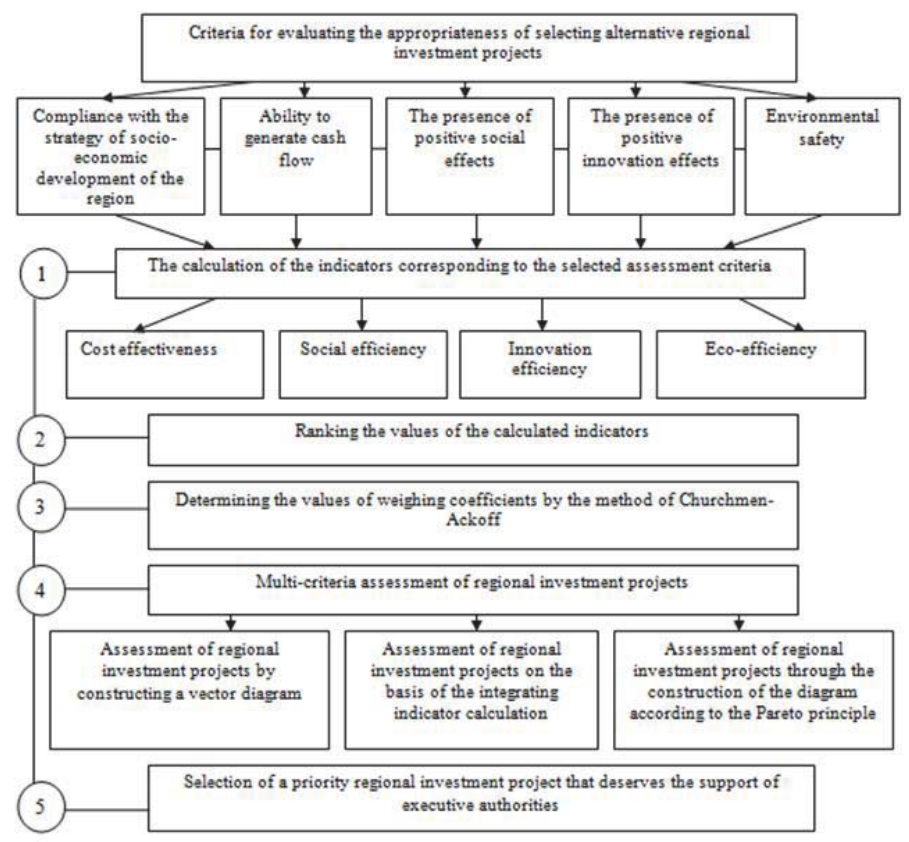

Scheme 3. Block diagram of the multi-criteria assessment method of regional investment projects efficiency

To improve the socio-economic development of the region certain tasks are set before the executive authorities, the main of which is further development of the system of state support of production sector enterprises through the implementation of regional investment projects aimed at increasing production volumes, the release of new products and providing jobs for the population. The implementation of investment policies is most likely to ensure stable growth of industrial production, increasing tax revenues to the regional budget (in the appropriate proportion) and will allow to accumulate funds for developing the social sphere of the region, improving living standards, reducing investment risks and increasing the innovative potential of the region. In light of the foregoing, the proposed approach was tested on regional investment projects, the participants of which were the production sector enterprises of the selected subject of the Russian Federation (Kursk Region), as these projects are capable of generating significant economic growth in the region. 


\section{Conclusions}

In conclusion, we should note that our studying the methods of analysis and assessment of regional investment projects efficiency has shown that they are not systematic. Considering all the factors that influence the development of the region through the realization of regional investment projects, we have substantiated the use of additional criteria for evaluating the efficiency of regional investment projects in terms of calculating the integrating performance indicator.

Taking into account these methodological shortcomings in the activities of regional authorities and the use of multicriteria assessment methods of regional investment projects efficiency will create conditions for increasing the efficiency of administrative decisions in the field of investment planning and provide on this basis the dynamic development of a particular region.

Applying practically the proposed methods for the assessment of regional investment projects will enable the executive authorities to make the right choice in favor of the highest priority regional investment project that deserves the support of the regional administration, and it will also provide the most complete and efficient use of existing capabilities and resources of the territory involved.

\section{References}

Korovina (Azzheurova) K. E. Minakova I. V. (2010) Modern mechanisms of management of regional investment system // The mechanism of the economy regulation. 3. Pp. $105-109$.

Azzheurova K. E. (2012) Improving the tools of management of regional investment projects // News of Saint-Petersburg State University of Economics. 2. Pp. 98-101.

Vodyanov A., Gavrilova O, Grishin L. (2008) Investment projects financed from the federal budget: methods of efficiency assessment /I Russian Journal of Economics. 1. Pp. 26-31.

Endovitskiy D.A. (2010) Investment analysis in the real sector of the economy. - M.: Finance and Statistics, $350 \mathrm{pp}$.

Vilenskiy P.L., Livshits V.N., Smolyak S.A. (2008) Assessment of efficiency of investment projects: theory and practice. - M.: Delo. 1142 pp.

Bystrov O.F., Pozdnyakov V.Ya., Prudnikov V.M., Pertsov V.V. (2008) Management of investment activity in the regions of the Russian Federation. - M.: INFRA-M. $358 \mathrm{pp}$.

Kovalev V.V. (2010) Methods of assessment of investment projects.- M.: Finance and Statistics. 372 pp.

Azzheurova K.E., Sergeev P.V. (2012) The identification of priority regional investment projects through the development of methods for assessing their efficiency // News of Orel State University of Economics and Trade. 1. Pp. 55-64.

Broll U., Roldán-Ponce A., Wahl J.E (2013) Regional investment under uncertain costs of location // Annals of Regional Science. 1 - P. 58-65.

Ageev A.A. (2011) Justification of the choice of the discount rate when determining the economic efficiency of an investment project // Finance and Credit. 20. Pp. 40-48.

Morgunova N.V. (2011) The role of investment strategy in the implementation of the innovation scenario of regional development /I Regional economy: theory and practice. 45. Pp. 22-28.

Sindyashkina E.N. (2010) The problems of evaluating the types of social effect in the realization of investment projects // Problems of forecasting. 1. Pp. 140-147.

Ruban A.Yu. (2009) Assessment of innovative efficiency of investment projects // Innovations and investments. 4. Pp.47-52.

Nuzhina I.P. (2010) Assessment of investment projects efficiency as a tool for ecological-economic regulation of investment and construction activities in the region // Innovations and investments. 6. Pp. 64-72.

Azzheurova K.E. (2012) Problems of assessment methodology of regional investment projects efficiency // Problems of financial support of innovative development of regional economy: collection of works from the Regional research-to-practice roundtable conference of students, lecturers, postgraduate students, specialists. Kursk. Pp. 7-16 